\title{
Anthropogenesis and the Soul
}

\author{
TERRENCE P. EHRMAN, C.S.C. \\ University of Notre Dame \\ ehrman.6@nd.edu \\ ORCID: 0000-0002-4046-9116
}

\begin{abstract}
The science of evolution acutely raises the perennial question of humankind's place in the world. How does the theological anthropology of humans as imago Dei relate to an evolutionary anthropology with human beings derived from ancestral hominid species? Evolutionary biologists disclose ever greater similarities and continuity between animals and humans. Is human distinctiveness simply continuous with other ancestral forms of life or is there any kind of discontinuity? The answers to these questions depend not only on zoological considerations but also on one's philosophy of nature. The standard anthropology within the Catholic Church is the dual-origin model: the human body originates through evolution, but the human soul is directly created by God. This formulation, however, is not without difficulties, primarily for its seeming Cartesian dualism of a body and soul as distinct substances. This paper develops the anthropology of David Braine who, drawing upon Aristotle, Thomas Aquinas, and Ludwig Wittgenstein, clearly situates humans as animals in great continuity with them. However, as linguistic animals who think in a medium of words, humans have a form of life-a soul-that transcends bodily processes. Braine's anthropology provides a more coherent anthropology to understand the continuity and discontinuity of the human person in phylogenetic relationship to other species within an evolutionary perspective
\end{abstract}

Keywords: evolution; language; hylomorphism; David Braine; Aquinas.

ScientiaetFides $8(2) / 2020,173-192$ 


\section{Introduction}

In the fourth century, Gregory of Nyssa made the astute connection between bipedalism and the human face, rational thought, and language. If humans were quadrupeds rather than bipeds and had no hands, "the various parts of his face would certainly have been arranged like those of quadrupeds, to suit the purpose of his feeding [...] and the form of the parts of the mouth would not have had the configuration proper for the use of speech [...] But now, as the hand is made part of the body, the mouth is at leisure for the service of reason” (Gregory 1994, §8.8). Nyssa anticipates contemporary evolutionary biologist Adam Wilkins who connects the evolutionary history of the human face to a mosaic of characteristics that evolved together: diet, nutrition, feeding behavior, evolution of hair, suckling requirements, brain size and complexity, language, and social interaction (Wilkins 2017, 212).

Nyssa and Wilkins exemplify opposing views of anthropogenesis. Nyssa is representative of the Christian belief in God the creator of all things and has a Christian anthropology of the human person as imago Dei. God created humans with a fitting bipedality that bespeaks both the rational nature of humans who look upward toward the heavens and their royal dignity compared to other animals (Gregory 1994, §8.1, 4, 8). Certainly, Nyssa predates an evolutionary understanding, but Christian theologians post-Darwin firmly continue to profess a divine origin to humans in addition to natural evolutionary causes. A not uncommon position among mainstream evolutionary biologists is a denial of a divine cause to the evolutionary origin of humankind. Wilkins recapitulates implicitly the philosophical presumption that natural and divine causes are mutually incompatible competitors: "To appreciate fully what makes something unusual, however, we must understand its origins. If the object of interest is biological, and if one does not believe divine creation to be its source, that awareness involves understanding its evolution" (Wilkins 2017, ix).

A Catholic Christian perspective applies a dual-origin model to anthropology in which the human body originates through evolutionary processes, but the human soul is directly and immediately created by God. This 
formulation, however, is not without difficulties. Its wording suggests not only a Cartesian dualism of the body and soul as distinct and independent substances, but also a god of the gaps, miraculous intervention by God in the procreation of each human being (Rahner 1965, 62-69).

The objective of this paper is to provide a more coherent anthropology and understanding of the human soul which affirms human identity as animals with an evolutionary origin but who are also intended by God and made in God's image. First, the philosophical framework of creation ex nihilo will be presented to frame how one understands the non-competitive relationship of natural and divine causes. Second, a brief history since Darwin of evolutionary anthropologies and their underlying philosophy of nature will be sketched. Third, the philosophical anthropology of David Braine will be introduced to better understand not only the nature of organisms in general but specifically the human person as both animal and spirit. Braine emphasizes humankind's animal form of intellectuality-language-as the key to the coherence of talking about "soul." The article concludes by bringing Braine's anthropology into conversation with the ecological and evolutionary concept of the niche.

\section{Divine and Natural Causes}

The framework in which to think about anthropogenesis and the human soul is set by the doctrines of the imago Dei and creatio ex nihilo which "teach us that the existing universe is the setting for a radically personal drama, in which the triune Creator calls out of nothingness those to whom He then calls out in love” (ITC 2004, §66). Humans participate in an evolutionary play taking place in an ecological theater (Hutchinson 1965). This natural drama is also concurrently a theo-drama.

Foundational to the compatibility between natural and divine causes is the distinction between God and creatures. Natural and divine causes inherently conflict with one another in a mutually exclusive zero-sum causation game when God and natural agents are conceived of univocally. Were God another being among many in the universe, then God's actions 
would be on the same causal plane as natural agents and in competition with them. However, this misunderstands who God is and how God acts in the world. God is not $a$ being or "thing" at all. Thomas Aquinas identifies God as subsistent being itself, ipsum esse subsistens, whose essence is identical with his existence (Aquinas 1948, I. Q. 3, a. 4; I. Q. 4, a. 2). Besides God who is, nothing else exists save what God calls into being ex nihilo.

A fundamental distinction exists between God and what God creates such that one can speak of an ontological duality between creator and creatures (Soskice 2010, 39). God's distinction from the world is of a different order than the distinction of one natural object from another. This "Christian distinction" between God and the world reveals the relation between them as creation, which is not a scientific category but a metaphysical one (Sokolowski 1995, 31-34). Thomas identifies creation as a relationship of dependence upon God for existence (Aquinas 1948, I. Q. 45, a. 3). Every natural thing only exists because God is the transcendent cause of that thing's existence at every moment. If God ceased giving being to something at any moment, it would not be at all. Thus, God creates-gives being-continually. Creation is not something that happened just in the past. It is an ongoing relationship of dependence even now.

God is radically transcendent over created reality, but this does not oppose God's radical immanence in all things. God's transcendence is not one of deistic removal from the world, nor is God's immanence one of univocity with the world (Tanner 1988, 45). The transcendent creator is also intimately present to all of creation. At every moment, God "acts immediately in all things" and is in them "innermostly" as their very source of being (Aquinas 1948, I. Q. 8, a. 1, response, ad. 3). As the cause of being, God does not compete, however, with the causation of the order of created reality (Burrell 2000, 169).

God is not only the cause of all beings but also the cause of all causes. God creates things with natures to be causal agents themselves. A Thomistic metaphysics understands a distinction yet concurrence between divine and natural causes which must be understood analogically, for God is not a cause among causes (Roszak 2017). God is the primary cause of the existence of 
all things, and he enables natural agents to be causes at a secondary level. Primary and secondary causes are both wholly necessary to explain some natural event. Primary and secondary causes do not act in a part-part relation as if God is partly the cause of some event and the natural agent a partial cause (Aquinas 1956, chap. 70, no. 8). Rather, each is wholly the cause of the event but at different levels. Scientists study natural or secondary causes, but they cannot study creation-the relationship of dependence something has upon God for existing.

\section{Human Phylogeny: Continuity and Discontinuity}

In 1863, Thomas Huxley identified the "question of questions for mankind-the problem which underlies all others, and is more deeply interesting than any other-" as "the ascertainment of the place which Man occupies in nature and of his relations to the universe of things" (Huxley 1863, 71). This question is more than a merely biological one about where the human species fits on a phylogenetic tree. It is also about epistemology-what branches of knowledge are required to understand who the human person is-and metaphysics - specifically the relationship between natural and divine causation.

As a central organizing theory within biology, neo-Darwinian evolution purports to explain the origin of species and their specific characteristics. Neo-Darwinian evolution sees the human intellect on a continuum with all other species. Darwin himself hypothesized that the human mind was explainable in terms of natural selection alone. In his Origin of Species, Darwin barely touched on human origins. The "production of the higher animals," particularly human beings themselves, Darwin would treat directly in his subsequent work, The Descent of Man (1871). In this latter work, Darwin applied his mechanism of natural selection firmly to embed humankind within evolutionary history and also to explain the unique characteristics of humankind, e.g., moral sense and intellectual powers. Darwin suggested that the similarities of behavior between humans and the great apes is "one of degree and not of kind" (Darwin 1936, 494-95). Human characteristics such as emotion, memory, and reason, Darwin sees present in various conditions 
in "lower animals" and endeavors to provide "the probable steps and means by which the several mental and moral faculties of man have been gradually evolved" (Darwin 1936, 494-95). In this respect, human traits are not analogous but homologous with the traits of other species. Homology indicates a common evolutionary origin whereas analogy lacks such an evolutionary commonality. For example, the forearm of humans, the wing of a bat, and the fin of a dolphin are homologous; the bone structure of each species stems from a common ancestral form that was modified over time in the respective species. The wing of an insect and the wing of bird, however, are analogous, for they arose independently in evolution. Beyond morphology, Darwin identifies human behaviors, formerly considered uniquely human, as homologous and on a continuum with other species.

Thomas Huxley forcefully argued for human continuity with other species, especially the great apes. Based on a "marvelous likeness of organization," Huxley classified humans, along with the apes and lemurs, as belonging to the Order Primate (Huxley 1863, 83, 124). Humans did not merit a separate Order, but he assigned them to their own separate family-Anthropini-within the primates. Six years later, Huxley divided the Primates into three sub-orders: Anthropidae (humans), Simidae (apes and monkeys), and Lemuridae (lemurs) (Huxley 1869, 99-100). Though recognizing structural distinctions in hand, foot, and brain, Huxley rejected any kind of physical "cerebral barrier" between humans and apes because of a fairly complete continuum in brain size among mammals (Huxley 1863, 115).

Huxley attributed the origin of human traits to the same natural causes that operate universally in evolution. Huxley takes a physicalist view of nature in that natural causes alone can explain the "production of all the phenomena of the universe," and this argues convincingly against "the intervention of any but what are termed secondary causes" (Huxley 1863, 128). The same physical causes that generated various genera and families of animals are "amply sufficient to account for the origin of Man" (Huxley $1863,125)$. He sees no rational ground for calling into question the origin of the human species from the "gradual modification of a man-like ape." Denying an absolute physical distinction between humans and other apes, 
Huxley sees the human faculties of feeling and intellect as homologously originating in lower forms of life; human fidelity and motherly love are present, respectively, in dogs and hens (Huxley 1863, 130-31). Despite this continuity, Huxley explicitly emphasizes the "vastness of the gulf" between humans, who alone possess intellect and reason, and the "brutes." Humans are from the brutes but not of them (Huxley 1863, 130).

Alfred Russell Wallace addressed the continuity and discontinuity of humans in relationship to other species and applied natural selection to human evolution. Because of human intellectual abilities, Wallace identified humans as "in some degree a new and distinct order of being" (Wallace 1864, clxvii). Like Huxley, Wallace recognized both the "striking resemblances" of human physical homology with the "anthropoid apes," and the "intellectual chasm" between them (Wallace 1864, clxix). Five years later, however, Wallace would reject the basic physicalist position of Huxley as Wallace emphasized human discontinuity, arguing that natural selection was insufficient to explain human moral and mental faculties that required "some form of purposive guidance connected to 'overruling intelligence'" (Benton 2009, 33). Darwin remonstrated Wallace for abandoning natural mechanisms, worrying that Wallace had "murdered" their child of natural selection (Glickman 2009, 36).

Darwin, Huxley, and Wallace's evolutionary origin and phylogenetic classification of humans need to be distinguished from their underlying epistemology and philosophy of nature.

Many proponents of evolution, both in the nineteenth century, such as Ernst Haeckel, and today, such as Richard Dawkins, "shrink wrap" biological theory with a metaphysical naturalism which presents an atheistic philosophical anthropology as intrinsic to evolution (Peters and Hewlett 2008, 85). It also presupposes a univocal causal order in which natural causes eliminate a need for divine causes. St. George Mivart, nineteenth century biologist and convert to Catholicism, accepts evolution but with a fundamentally different epistemology and natural philosophy than Darwin and Huxley.

Mivart firmly believed in evolution and published works on primate phylogeny and placed humans firmly among the apes. In comparison to 
Huxley who separated humans, higher apes, and lemurs into three different sub-orders of primates, Mivart proposed only two sub-orders: within the Anthropoidae, he lumped together humans and higher apes (along with monkeys, baboons, and marmosets); the second sub-order, the Lemuroidae, contained lemurs, galagos, tarsiers, etc. (Mivart 1864, 615). Mivart recognized a physiological and anatomical continuity, yet also a "wondrous chasm" between humans and the rest of the sub-order.

Beyond the biological realm, Mivart rejected the Darwinian supporters' philosophy of science and nature. He critiqued Darwin's anthropology that identified humans as no more than animals, differing only in degree and not in kind (Mivart 1876, 180). Mivart sees rationality and "intellectual language" as a distinction of kind from the cognitive faculties of animals (Mivart 1898, 189-214). Humans are intellectual animals and moral agents whose freedom opens them to an "infinite future" which is a profound distinction from all else in the "kingdom of material beings" (Mivart 1876, 180,184). Darwin's anthropological error results from "a radically false metaphysical system” that eliminates the nonphysical and divine as causes (Mivart 1876, 184). Darwin and Huxley analyze and categorize the human person from a purely zoological perspective. Mivart, an anatomist himself, recognizes the importance of zoological study of humans as animals, but he recognizes the nature of humans as compound of two orders-material and spiritual (Mivart 1871, 283). Thus, one must consider the "man in his totality and not merely from the point of view of anatomy” (Mivart 1876, 182).

In contrast to Darwin's opposition of divine and natural causes, Mivart drew upon a Thomistic metaphysics wherein divine and natural causes can operate concurrently. Mivart wrote about creation in three senses: 1) direct or supernatural action; 2) derivative creation or physical action; and 3) hyperphysical action (Mivart 1871, 252-53). The latter two belong to the order of nature and do not oppose a concurrent divine action. Derivative creation corresponds to secondary causation whereas hyperphysical action is voluntary conscious, intellectual activity. The human intellectual soul is hyperphysical. Within this metaphysical framework, "it is no longer absolutely necessary to suppose that any action different in kind took place in 
the production of man's body, from that which took place in the production of the bodies of other animals, and of the whole material universe" (Mivart 1871, 281-82). Knowing from Thomistic hylomorphism that the rational human soul cannot be educed from matter but is directly created by God (Aquinas 1948, I. Q. 75, a. 6, ad. 1), Mivart proposed a dual-origin to the human person: the human soul is directly created by God, but the human body evolved by natural physical laws of derivative or secondary creation (Mivart 1871, 287).

Mivart's dual-origin theory has become a standard position within the Catholic Church. Eighty years later, in the first papal statement on evolution and theological anthropology, Pope Pius XII recapitulated Mivart's dual-origin model. Pius XII cautiously allowed circumspect scientific and theological discussion regarding the "doctrine of evolution, in as far as it inquires into the origin of the human body as coming from pre-existent and living matter," but he holds firmly to the Catholic faith that "souls are immediately created by God” (Pius XII 1950, §36). Almost a half century later, Pope John Paul II reaffirmed Pius XII's dual-origin model of human origins while explicitly addressing the question this raises about human continuity within an evolutionary framework (John Paul II 1996, §3,5).

In the arc from Mivart to Pius XII and John Paul II, is the dual-origin model of the human person persuasive today? To a scientific community, many of whom adopt a physicalist or eliminative materialist position, any talk of an immaterial soul created by God is readily dismissed as fanciful and magical. The intervention of God from outside the natural causal nexus seemingly introduces a causal gap. Philosophically, the duality of a soul created by God and a body formed by evolution seems beholden to a Cartesian metaphysics in which body and soul are distinct substances.

In between Pius XII and John Paul II, Karl Rahner engaged this specific issue of the dual-origin theory of human evolutionary origins (Rahner 1965). Critical to framing anthropology for Rahner, as for Mivart, is metaphysics. God as the transcendent ground of all reality and humans as a unity of matter and spirit are metaphysical starting points for any subsequent scientific epistemology. Holding firm to a Thomistic distinction between primary and 
secondary causes, Rahner wonders if the creation of a spiritual soul becomes an exception to that distinction. He answers negatively as he explains the coming to be of humans evolutionarily as a natural self-transcending movement, a becoming, however, whose cause and ground is absolute Being. God gives to the nature or essence of humans the capacity for self-transcendence. In anthropogenesis, God's activity "causes the operation of the creature which exceeds and transcends its own possibilities" (Rahner 1965, 101).

The next section will discuss the philosophical anthropology of David Braine who starts with an understanding of the unity of the human person as animal and spirit from which he develops a robust hylomorphic metaphysics and through an analysis of human language provides a coherent anthropology in which to understand non-dualistically the dual-origin theory.

\section{Language and the Human Soul}

David Braine argues for a recovery of non-dualistic "soul" language in the context of understanding the human person whose animal form of life is in community with the rest of the physical and biological world (Braine 1992, 496). Braine emphasizes that "what we say about the soul is always derivative from and determined by ... what we have to say about this or that kind of living bodily being” (Braine 1992, 511). Braine's main argument is that humans have a form of bodily life-linguistic understanding and thinking in a medium of words-that transcends the body and its processes. This transcendence provides a context for understanding the origin of the soul, or rather of the human person who is animal and spirit, by God.

David Braine presents an anthropology which seeks to preserve the unity of the human being, specifically as a living human organism, and at the same time to escape from the Cartesian dichotomy of mind and body which undergirds contemporary philosophical anthropology (Braine 1992). He first develops a fundamentally Aristotelian anthropology coupled with the thought of Ludwig Wittgenstein which fills the space between the deficient poles of dualism and materialism to restore the psychophysical unity of the human person, and then secondly, rooted in Thomas Aquinas' anthropology 
and understanding of esse, develops what is unique to humans as those who have linguistic understanding and think in a medium of words.

Braine draws upon Aristotle's hylomorphic anthropology which provides a more robust ontology to account for and describe humans (and other organisms) holistically as unified bodily beings. For Aristotle, all living beings are living bodies, a unity of form (or soul) and matter. Contrary to a modern Cartesian ontology of universal matter which is fundamental to what exists, what is fundamental for Aristotle is not matter but primary substances, such as a daffodil, a damselfly, and a human being. Stones, bacteria, plants, animals, and persons do not share "one way of being a concrete thing or substance" but have "different modes of acting ... and different logical types of relation towards other things" (Braine 1992, 144). As a substance, the organism is to be treated and understood as a whole, a psychophysical whole in the case of higher animals and humans.

Aristotle's notion of the soul as the form of the body is not a dualistic, Cartesian notion of the soul which alone has mental properties reserved to it. Thinking for Aristotle is a natural part of the life of humans. Descartes' separation of the mind from matter, of Cartesian psychology from Cartesian physics, creates the mind-body interaction problem, but for Aristotle, "psychology is a part of physics, that is, of the general theory of nature; psychology therefore has an Aristotelian conception of matter built in" (Cohen 1992, 60). Humans (and higher animals) are psychophysical wholes, focalized subjects with irreducibly hybrid powers. This Aristotelian holistic view presumes an inseparability between perception and behavior such that substances, not events, are the primary agents of explanation and causation.

Inherent to this agent-causality is teleological explanation of phenomena without recourse to mechanical laws of nature. The recovery of substances as agents also brings with it a kind of explanation of phenomena that material causation is insufficient to explain. Teleological explanation does not entail that "some end is an efficient cause" but that a richer explanation than the material or physical is needed to account for a phenomenon that relates to a new kind of ontology, namely psychophysical wholes which act as agents (Braine 1992, 230). Like Mivart’s neo-Aristotelianism, Braine's philosophy of 
nature rejects physicalism in that humans (and animals) are not completely explainable by the laws of matter and physics (Braine 1992, 289).

Braine rejects physicalism and materialism because of holism and its intrinsic teleology. Humans and higher animals are not simply material entities or mechanical systems completely explainable by material or efficient causation. Such animals are psychophysical wholes, conscious agents who act teleologically and not as billiard balls. Because the physical and psychological are inseparable, an explanatory account of consciousness requires an "enlargement of ontology" (Braine 1992, 296). Braine distinguishes two structures of consciousness: the perceptual consciousness shared by humans with higher animals and the global structure distinctive of human consciousness (Braine 1992, 301). Though humans and higher animals are psychophysical wholes not completely explainable as mechanical systems, mechanical or physical processes are internal to acts of perceptual consciousness, such as perception, imagination, emotion, and intention (Braine 1992, 449). Distinctive of the psychophysical activity of human consciousness compared to higher animals is language. Braine argues that mechanical processes are not internal to linguistic understanding and thus indicates the non-dualistic transcendence of the human person over the body.

Human animals are psychophysical wholes who have the capacity for using language, and this characteristic distinguishes human animals from all other animals. Speech is not something belonging to a disembodied mind but is a proper animal activity as it involves voice produced by bodily parts such as lungs, pharynx, tongue, teeth, and lips. Braine does not begin, as Thomas Aquinas does, with thinking and understanding, "but with the particular kind of psychophysical activity which defines the difference between the human being and other animals, namely language” (Braine 1992, 348). Drawing upon Ludwig Wittgenstein, Braine's central thesis concerning language and thought is that rationality can only be conceived in terms of what is "linguistically expressible" (Braine 1992, 351, 355).

Just as the focalized human subject has a simplicity as an irreducible psychophysical whole, Braine argues that the subject of thought and the operations of thought also have a simplicity and indivisibility (Braine 1992, 
400). This indivisibility and simplicity of thought does not admit of internal processes. The expression of thought has a teleology analogous to the teleology of psychophysical beings, which, however, does not exclude the role of the physical. Thinking requires the body for expression whether in speaking or writing, but given thought's teleology and simplicity, Braine does not think that linguistic understanding or thinking in a medium of words have physical processes internal to them or have bodily states or activities.

Braine distinguishes between two levels of language, namely langue and parole. Langue refers to the conventional meaning of words as dictionary-items which have meanings in their own right. Parole refers to the meaning of language as used in speech; it is the use of the understanding of langue. Langue alone is limited, but its expression in parole opens a door to infinite possibilities. The fecundity, flexibility, and extensibility of the understanding of parole which uses words in an "indefinite number of logically distinguishable types of use" is lacking in any material correlate (Braine 1992, 451). Linguistic understanding also requires a judging subject and self-reflection. Braine reformulates Aquinas' idea that "no material faculty can reflect upon itself," as "there can be isomorphism between part of the material faculty and the whole but nothing corresponding to a judgement by the whole in regard to the whole-no reproduction in the material organism of the structure whereby the organism in critical judgement reflects upon itself or critically (reflectively) judges” (Braine 1992, 472). Thus, Braine argues that linguistic understanding and thinking in a medium of words is not a bodily operation.

Braine, like Wittgenstein, did not think there can be an organ of thought as there is an organ for seeing. The brain can be called the organ of experience, meaning that the brain provides a sensory interpretation of the world, but the human person as a psychophysical whole is the subject who sees, understands, speaks, and thinks. Thinking is not the operation of an inner organ but occurs in a medium of words such that the voice is a better candidate for the organ of thought than the brain (Braine 1992, 449-50).

Wittgenstein's demolition of the Cartesian domination of Western thought allowed a recovery of pre-Cartesian manners of thought, particularly 
that of Aquinas who preserved the unity of the human person with his notion of the soul as the subsistent form of the body and who also like Wittgenstein argued that there is no organ of thought in the body (McCabe 2005, 2). Braine draws upon the linguistic parallel between Aquinas and Wittgenstein. Aquinas had a "keen attention to logic and language," specifically in relation to thought, understanding, and his theory of the knowledge of reality and of God (Burrell 2008, xii). His treatment of thinking and knowing anticipated what "Wittgenstein says about meaning and understanding” (Davies 2005, xii). Braine explains the essential connection between thought and language by starting from the language end like Wittgenstein and not the thought end like Aquinas. Given this connection, Braine accesses the insights of Aquinas concerning the soul and esse to express the non-dualistic transcendence of the existence of the human person over the physical, biological, and even over death.

The acts of human linguistic understanding and thinking in a medium of words are human activities which transcend the body. These are acts of a human being who, as Braine concludes by drawing upon Aquinas' notion of esse, has an esse, an existence, which transcends the body (Braine 1992, 537-42). Non-linguistic animals are types of beings, each with a certain form of life or way of existing. They perceive, imagine, remember, and suffer emotion, but all these operations of these kinds of organisms, all the operations of their souls, are bodily processes (Braine 1992, 516). Linguistic animals, however, have a new way of being or existing which includes operations (linguistic understanding and thinking) which are not bodily operations. Thus, the existence or esse of human beings transcends the physical and biological. The human soul, then, as the form of the body, as that which makes humans to be the kind of organisms they are, must have an existence or esse which transcends the body. Braine, however, emphasizes the holism of the human person as transcendent. The human being exists in its own right because he or she has "states and operations which are not bodily. And it is because we can speak of the human being as existing in its own right that we can speak derivatively of the human soul in this way, and not the other way around" (Braine 1992, 350). 
Braine's anthropology and broader philosophy of nature allows a more coherent understanding of the dual-origin model of the human person in an evolutionary perspective, preserving the continuity and discontinuity between humans and ancestral hominids without introducing foreign interventionist causes. Because humans and higher animals both possess psychophysical natures, the procreation of any hominid (e.g., human, Neanderthal, chimpanzee, gorilla, or orangutan) by respective parent hominids is not a "merely physical process" (Braine 1992, 530). For non-human animals, however, their forms of life have no characteristics or operations which exist in their own right apart from the body compared to humans who do. The coming to be of a human being includes the coming to be of something which does exist in its own right. This is part of the ordinary course of nature and not a breach in the causal order. Thus, "the creation of the human soul is not the insertion of an alien element into an otherwise self-contained and self-sufficient physical field" (Braine 1992, 530). This is most coherent in a theological perspective of creation in which everything that is depends upon God the Creator for existence. The origin of any human person implies that "a creative act enters into the natural processes of procreation in every such human coming into existence, but such a creative act will not break the order of the world but serve to preserve it" (Braine 2013, 154). As the primary cause of existence and of natural causes, God causes the existence of a baby chimpanzee through the sexual activity of its parents, but this chimpanzee soul has no existence of its own apart from the body. In human procreation, God causes a new human soul to come into existence, but this soul does have an existence (esse) of its own. In either case, God is the cause of the existence and sustenance of the animal's soul-whether chimpanzee or human. God does not intervene into the natural order in either case. Intervention implies a prior absence into which one enters, but God as transcendent primary cause is immanent and present in all things already as the cause of their existence.

Braine's philosophical anthropology and understanding of the divine creation of the human soul parallels Rahner's in many ways. Both rely on a prior metaphysical understanding of God' nature, the distinction between 
primary and secondary causation, and the unity of the human person as animal (or matter) and spirit. For both, the origin of the soul is not a causal exception of divine intervention but of normative divine and natural causal concursus that illuminates the transcendent nature of the human person. Braine's focus on language, furthermore, provides a context in which evolutionary theories of language origin can be explored.

\section{Conclusion}

Language is the key to understanding the human form of life compared to other hominid forms of life. Language shows how human thought and existence transcend the body but at the same time require the body for expression. Braine's anthropology situates humans well within the evolutionary drama because it emphasizes the bodiliness of the human animal. It allows for understanding the biological homologies of humans with ancestral forms of life. However, through linguistic understanding and thinking in a medium of words, it also emphasizes the discontinuity of the human person from ancestral forms. Human behaviors become analogous to ancestral forms and no longer homologous (Sloan 2015). In the emergence of Homo sapiens, Braine sees language as expressing "discontinuity underlying apparent continuity” with other hominids and hominins. Braine thinks only Homo sapiens and not other hominins such as Neanderthals had linguistic understanding (Braine 2014, 233-42).

The human situation can be brought into correspondence with the ecological and evolutionary notion of the niche. Anthropologists and evolutionary biologists locate humans within a socio-cognitive niche in addition to an ecological niche. Humans have a "distinct way of being in the world" given their language, intellect, will, freedom, cooperation, and culture (Whiten and Erdal 2012; Fuentes 2014, 245). The situation or niche of non-human hominids, such as the great apes, is one limited to present episodes and immediate responses to the environment (Donald 1991, 149). Even extinct hominins such as Neanderthals, Denisovans, and Flores did not enter the linguistic niche that Homo sapiens was able to enter (Fuentes 2014, 
246-47). Because of language, in contrast, the human situation is global. Language lays the human person open to new horizons that transcend the local and immediate and even material such that "one's perspectives are not limited to one's immediate opinions and interests, one's locality and tribe and its customs, but extend to questions of 'fact' or 'objective truth', the good and the right, one's larger environment and community with nature, the cosmos and to God" (Braine 1992, 543). The human niche opens into the divine as humans are those animals who are capax Dei.

The human animal is a person who has the capacity to enter into dialogue with the tri-personal God. The very word "person" derives from the Greek word prosopon which was a mask worn by actors on the theatrical stage that did not so much hide someone but made one's dramatic face present. The Latin persona parallels this theatrical origin: "it was a mask that projected character per-sona, through sound" (Vessey 2014, 127). Humans have a wonderful kinship consanguinity with all the other actors on the stage, but they, who were formed out of the dust of the earth and who stand upright with the breath of God in them, possess a spiritual nature that bespeaks their obligate bipedality. They are part of the evolutionary play but also the theo-drama in which God creates them and calls them to share in his friendship. The origin of the human person evolutionary is distinguished by a linguistic relation to God. "The first Thou that-however, stammeringly-was said by human lips to God marks the moment in which spirit arose in the world” (Ratzinger 2005 "Belief," 142). Humans are linguistic animals who think in a medium of words, and with their face, long to see beyond the veil that obscures their vision, that they will see God face to face (1 Cor 13:12).

\section{References}

Aquinas, Thomas. 1948. Summa Theologica. Translated by Fathers of the English Dominican Province. New York: Benzinger Brothers, Inc.

Aquinas, Thomas. 1956. Summa Contra Gentiles. Book Three: Providence Part I. Translated by Vernon J. Bourke. Notre Dame: University of Notre Dame Press. 
Benton, Ted. 2009. “Race, Sex and the 'Earthly Paradise’: Wallace Versus Darwin on Human Evolution and Prospects.” Sociological Review 57 Supplemental 2: 23-46. Braine, David. 1992. The Human Person: Animal and Spirit. Notre Dame: University of Notre Dame Press.

Braine, David. 2013. “Life and Human Life: Their Nature and Emergence.” In The Missing Link, edited by Roy Abraham Varghese, 132-160. Landam: University Press of America.

Braine, David. 2014. Language and Human Understanding. Washington, D.C.: The Catholic University of America Press.

Burrell, C.S.C., David B. 2000. "Freedom and Creation in the Abrahamic Traditions.” International Philosophical Quarterly XL.2: 161-71.

Burrell, C.S.C., David B. 2008. Aquinas: God and Action. Scranton: University of Scranton Press.

Cohen, S. Marc. 1992. “Hylomorphism and Functionalism.” In Essays on Aristotle's De Anima, edited by Martha C. Nussbaum and Amélie Oksenberg Rorty, 57-73. Oxford: Clarendon.

Darwin, Charles. 1936. The Origin of Species and the Descent of Man. New York: The Modern Library.

Davies, Brian. 2005. “Introduction.” In. The Good Life: Ethics and the Pursuit of Happiness, edited by Herbert McCabe, vii-xiii. London: Continuum.

Donald, Merlin. 1991. Origins of the Modern Mind: Three Stages in the Evolution of Culture and Cognition. Cambridge: Harvard University Press.

Fuentes, Agustín. 2014. "Human Evolution, Niche Complexity, and the Emergence of a Distinctively Human Imagination.” Time and Mind 7: 241-57.

Glickman, Stephen. 2009. “Charles Darwin, Alfred Russell Wallace, and the Evolution/ Creation of the Human Brain and Mind.” Gayana 73 (Supplemental): 32-41.

Gregory of Nyssa. 1994. "De hominis opificio.” In Nicene and Post-Nicene Fathers. Vol. 5. Gregory of Nyssa: Dogmatic Treatises, etc. 2nd Series, edited by Philip Schaff and Henry Wace. Peabody: Hendrickson Publishers.

Hutchinson, G. Evelyn.1965. The Ecological Theater and the Evolutionary Play. New Haven: Yale University Press.

Huxley, Thomas H. 1863. Evidence of Man's Place in Nature. New York: D. Appleton and Co.

Huxley, Thomas H. 1869. An Introduction to the Classification of Animals. London: John Churchill.

International Theological Commission (ITC). 2004. Communion and Stewardship: Human Persons Created in the Image of God. 
http://www.vatican.va/roman_curia/congregations/cfaith/cti_documents/rc_con_ cfaith_doc_20040723_communion-stewardship_en.html (accessed March 30, 2020).

John Paul II. 1996. Message to the Pontifical Academy of Sciences: On Evolution. http:// www.ewtn.com/library/PAPALCOC/JP961022.HTM (accessed March 30, 2020).

McCabe, O.P., Herbert. 2005. The Good Life: Ethics and the Pursuit of Happiness. London: Continuum.

Mivart, St. George. 1864. "Notes on the Crania and Dentition of the Lemuridae." Proceedings of the Zoological Society of London. 32: 611-48.

Mivart, St. George. 1871. On the Genesis of Species. London: Macmillan and Co.

Mivart, St. George. 1876. Lessons from Nature as Manifested in Mind and Matter. London: John Murray.

Mivart, St. George. 1898. The Groundwork of Science: A Study of Epistemology. London: John Murray.

Peters, Ted and Martin Hewlett. 2008. Can You Believe in God and Evolution? Nashville: Abingdon Press.

Pius XII. 1950. Humani generis. http://www.vatican.va/content/pius-xii/en/encyclicals/ documents/hf_p-xii_enc_12081950_humani-generis.html (accessed March 30, 2020).

Rahner, Karl. 1965. Hominisation. Translated by W. T. O’Hara. New York: Herder and Herder.

Ratzinger, Joseph. 1995. In the Beginning: A Catholic Understanding of the Story of Creation and the Fall. Grand Rapids: W.B. Eerdmans Pub. Co.

Ratzinger, Joseph. 2005. “Zum Personverständnis in der Theologie.” In Dogma und Verkündigung, 201-19. Donauwörth: Erich Wewel.

Ratzinger, Joseph. 2005. "Belief in Creation and the Theory of Evolution." In Dogma and Preaching: Applying Christian Doctrine to Daily Life, edited by Michael J. Miller, 131-42. Translated by Michael Miller. San Francisco: Ignatius Press.

Roszak, Piotr. 2017. "Analogical Understanding of Divine Causality in Thomas Aquinas.” European Journal for Philosophy of Religion 9:133-53.

Sloan, Phillip. 2015. “Questioning the Zoological Gaze.” In Darwin in the Twenty-First Century: Nature, Humanity, and God, edited by Phillip R. Sloan, Gerald McKenny, and Kathleen Eggleson, 232-66. Notre Dame: University of Notre Dame Press.

Sokolowski, Robert. 1995. The God of Faith and Reason. Washington, D.C.: The Catholic University of America.

Soskice, Janet. 2010. “Creatio ex nihilo: its Jewish and Christian Foundations." In Creation and the God of Abraham, edited by David Burrell, Carlo Cogliati, Janet Soskice, and William Stoeger, 24-39. Cambridge: Cambridge University Press. 
Tanner, Kathryn. 1988. God and Creation in Christian Theology: Tyranny or Empowerment? Oxford: Basil Blackwell.

Vessey, David. 2014. “The Role of the Concept 'Person' in Gadamer's Philosophical Hermeneutics.” American Catholic Philosophical Quarterly 88: 117-38.

Wallace, Alfred Russell. 1864. "The Origin of Human Races and the Antiquity of Man Deduced from the Theory of 'Natural Selection." Journal of the Anthropological Society of London 2: clviii-clxxxvii.

Whiten, Andrew and David Erdal. 2012. "The Human Socio-Cognitive Niche and Its Evolutionary Origins.” Philosophical Transactions of the Royal Society B 367: 2119-29.

Wilkins, Adam. 2017. Making Faces: The Evolutionary Origins of the Human Face. Cambridge: The Belknap Press of Harvard University Press. 